\title{
Efeito de Estratégia de Suplementação com Concentrado no Desempenho de Cabras Mestiças Saanen, em Dois Sistemas de Produção ${ }^{1}$
}

\author{
Vicente de Paulo Macedo ${ }^{2}$, Júlio Cesar Damasceno ${ }^{3}$, Geraldo Tadeu dos Santos ${ }^{3}$, \\ Elias Nunes Martins ${ }^{3}$, Francisco de Assis F. Macedo ${ }^{3}$, Marcos Weber do Canto ${ }^{3}$
}

\begin{abstract}
RESUMO - O experimento foi conduzido com os objetivos de avaliar o desempenho de cabras leiteiras mestiças Saanen, submetidas a duas estratégias de suplementação com concentrado (ESC): 30\% das exigências diárias em energia líquida (NRC, 1981), supridas pelo concentrado, da $3^{\mathrm{a}}$ semana até o final de lactação (ESC.1) ou $60 \%$ das exigências da $3^{\mathrm{a}}$ à $13^{\mathrm{a}}$ semana de lactação e $15 \%$ da $14^{\mathrm{a}}$ semana até o final da lactação (ESC.2) e avaliar a resposta dos animais à estratégia de suplementação com concentrado em sistema de produção semiconfinamento e em pastagem. Foram utilizados 31 animais em delineamento completamente casualizado. O sistema de produção teve efeito no consumo total de concentrado e produção total de leite; no sistema em pastagem, os valores para essas duas variáveis foram superiores. A suplementação com concentrado afetou o consumo total de concentrado e a relação produção de leite/consumo de concentrado. Maior valor para relação produção de leite/consumo de concentrado e menor para consumo total de concentrado foram obtidos para ESC.1. O peso corporal foi afetado pelo sistema de produção, resultando maior valor para o sistema em pastagem. O peso e a condição corporal apresentaram respostas variadas à suplementação com concentrado, em função do sistema de produção. No sistema de semi-confinamento, a ESC.2 resultou em maior valor para condição corporal e o peso corporal não sofreu efeito. No sistema em pastagem, os maiores valores do peso e condição corporal foram encontrados para ESC.1. Os parâmetros reprodutivos não sofreram efeito da estratégia de suplementação com concentrado e sistema de produção.
\end{abstract}

Palavras-chave: peso e condição corporal, produção de leite

\section{Effect of Supplementation Level with Concentrate on Performance of the Crossbred Saanen Dairy Goats, in two Production Systems}

\begin{abstract}
The experiment was carried out to evaluate the performances of cross breed Saanen dairy goats submitted to two strategies of supplementation with concentrate $30 \%$ of daily requirements in net energy (NRC, 1981) supplied by concentrate, from third week until the end of lactation (ESC.1) or $60 \%$ of requirements from the $3^{\text {rd }}$ to the $13^{\text {th }}$ week of lactation and $15 \%$ from $14^{\text {th }}$ until the end of lactation (ESC.2); and evaluate the animal response to these strategies of supplementation with concentrate in a semi-confined or pasture systems. Thirty one animals were used in a completely randomized design. The system of production affected the total intake of concentrate and total milk production; at pasture system the values for these two variables were higher. The supplementation with concentrate affected the total intake of concentrate and total production of milk and the relation of milk/consumption of concentrate. The highest value for relation of milk/consumption of concentrate and the least for the total consumption of concentrate were obtained at ESC.1. Body weight affected of the system of production, resulting in a higher value to the system of pasture. Weight and body condition had different responses to he supplementation with concentrate according to the system of production. The semi-confined system ESC. 2 resulted in a higher value to the body condition; the body weight was no affected. At pasture system the highest values for weight and body condition were obtained in the supplementation with concentrate ESC.1. Reproductive parameters did not affect supplementation with concentrate and system of production.
\end{abstract}

Key Words: body condition and weight, milk production

\section{Introdução}

A produção de leite, a partir de cabras leiteiras, vem apresentando aumento nos últimos anos no Brasil, devido, principalmente, à necessidade de se buscarem novas alternativas de produtos de alta qualidade e rentabilidade, que é o caso do leite e seus derivados.

Em busca de melhor produtividade, estão sendo utilizados animais que tenham potencial genético para produção. A nutrição e o manejo alimentar de cabras leiteiras são os principais responsáveis pelo aumento da produtividade dos animais, refletindo diretamente

\footnotetext{
${ }^{1}$ Parte da dissertação do primeiro autor apresentada ao PPZIDZOIUEM, Maringá, como um dos requisitos para a obtenção do título de Mestre em Produção Animal.

2 Zootecnista, aluno do curso de pós-graduação em Zootecnia - UNESP - Botucatu.

${ }^{3}$ Professores do Departamento de Zootecnia da UEM, Av. Colombo, 5790 - 87020-900, Maringá - PR. E.mail: jcdamasceno@uem.br
} 
no nível de rentabilidade da criação.

A maioria das informações existentes na literatura sobre alimentação de cabras leiteiras é referente às criadas em sistema de confinamento. Pouca informação existe sobre sistemas que utilizam o pasto como importante fonte de nutrientes, principalmente, quanto ao uso de alimentos concentrados como suplementação.

Outro sistema utilizado é o semi-confinamento; no qual os animais têm acesso à pastagem apenas em algumas horas por dia, aproximadamente, das 9 às $18 \mathrm{~h}$, permanecendo confinados em instalações com piso ripado, no restante do dia. Esta estratégia visa a reduzir a ingestão de larvas infectantes de helmintos, uma vez que a verminose se constitui em um dos principais problemas sanitários para estes animais.

A produção de leite depende da aptidão leiteira da cabra, da qualidade do alimento e nível de consumo de matéria seca pelo animal. Sob regime de pastejo, o consumo de matéria seca é grandemente afetado pela altura da planta, relação folha-caule e densidade volumétrica, assim como pela disponibilidade de pasto (Santos, 1994). O pastejo ótimo representa o uso de taxa de lotação, compatível com a capacidade de suporte.

Em situações onde os animais produzem quantidade de leite maior que as pastagens possam sustentar, é fundamental que se recorra à suplementação com concentrados, possibilitando aos animais expressarem o potencial de produção (Lucci, 1993).

Em pesquisa realizada com cabras leiteiras, Damasceno et al. (1997) obtiveram aumentos lineares na produção de leite e no conteúdo de proteína do leite com o aumento do concentrado fornecido. Resultado semelhante foi encontrado por Singh (1996), que obteve maior produção de leite e ganho de peso com o aumento dos níveis de concentrado. Entretanto, Vilela et. al. (1997) relataram resultados, indicando que a melhor estratégia seria fornecer maiores quantidades de concentrado nos momentos iniciais da lactação, reduzindo-as, a seguir.

Respostas ao regime de suplementação dependerão, essencialmente, da qualidade do volumoso ingerido, do potencial genético dos animais e das condições de criação dos animais. Pressupõe-se que animais submetidos a condições inadequadas de criação, resultarão em problemas sanitários e nutricionais, reduzindo a resposta à suplementação.

O presente trabalho teve como objetivos: a) avaliar o desempenho de cabras leiteiras cruza Saanen, submetidas a dois regimes de suplementação com concentrado (30\% das exigências diárias em energia líquida, supridas pelo concentrado, da $3^{\mathrm{a}}$ semana até o final da lactação ou $60 \%$ das exigências da $3^{\mathrm{a}}$ à $13^{\mathrm{a}}$ semana de lactação e $15 \%$ da $14^{\mathrm{a}}$ semana até o final de lactação); b) avaliar a resposta dos animais a estes regimes de suplementação, em sistema semiconfinamento ou em pastagem.

\section{Material e Métodos}

O experimento foi conduzido no setor de caprinocultura da Fazenda Experimental de Iguatemi (FEI), Universidade Estadual de Maringá, no período de agosto de 1997 a outubro de 1998. Foram utilizadas 31 cabras em lactação, com grau de sangue 3/4, 7/8 e 15/16 da raça Saanen, e ordem de lactação $1^{\mathrm{a}}, 2^{\mathrm{a}}$, $3^{\mathrm{a}}$ e $4^{\mathrm{a}}$. Para a formação dos lotes, foram levados em consideração: ordem de lactação e grau de sangue.

O setor conta com um aprisco, dividido em boxes individuais, contendo bebedouros, cochos e canzis para alimentação dos animais, sala de ordenha e uma área de pastagem de estrela africana (Cynodon nlemfuensis).

Os tratamentos testados foram resultados de um arranjo fatorial $2 \times 2$, em que o fator 1 correspondeu a duas estratégias de suplementação de concentrado e o fator 2, a dois sistemas de produção.

Foram testadas as seguintes estratégias de suplementação de concentrados: $30 \%$ das exigências em energia líquida (NRC, 1981), da $3^{\mathrm{a}}$ semana até o final da lactação (ESC.1); 60\% das exigências em energia líquida diária, da $3^{\mathrm{a}}$ à $13^{\mathrm{a}}$ semana; e $15 \%$ da $14^{\mathrm{a}}$ semana até o final da lactação (ESC.2). A quantidade de concentrado fornecida foi corrigida, semanalmente, de acordo com a produção de leite e peso vivo dos animais.

Estas estratégias de suplementação com concentrado foram avaliadas em dois sistemas de produção: semi-confinamento (Sis.1) e em pastagem (Sis.2).

Apresentam-se nas Tabelas 1 e 2 as composições químicas do concentrado, pasto e feno, utilizados ao longo do período experimental.

Os concentrados fornecidos aos animais em crescimento e aos adultos continham $72 \%$ de milho e $28 \%$ de farelo de soja, $75 \%$ de milho e $25 \%$ de farelo de soja, respectivamente.

Foi considerado animal em crescimento aquele de primeira ou segunda lactação. Para o cálculo das exigências nutricionais, consideraram-se, além da produção de leite e peso vivo dos animais, taxas de 
Tabela 1 - Composição química e digestibilidade in vitro da matéria seca dos concentrados

Table 1 - Chemical composition and in vitro dry matter disappearance of concentrates

Variáveis (\% da MS) $\quad$ Concentrado 1 Concentrado 2

Variables $(\% D M) \quad$ Concentrate $1 \quad$ Concentrate 2

\begin{tabular}{ccc}
\hline $\mathrm{PB}^{1}$ & 21,37 & 21,70 \\
$C P^{1}$ & 14,68 & 14,30 \\
$\mathrm{FDN}^{2}$ & 5,06 & 4,95 \\
$N D F^{2}$ & 89,59 & 87,30 \\
$\mathrm{FDA}^{3}$ & & \\
$A D F^{3}$ & $\mathrm{DIVMS}^{4}$ & \\
$I V D M D^{4}$ & &
\end{tabular}

Concentrado $1=$ Animais em crescimento; Concentrado $2=$ Animais adultos (Concetrate $1=$ Growing animals; Concentrate $2=$ Mature animals).

1 Proteína bruta.

${ }^{2}$ Fibra em detergente neutro.

${ }^{3}$ Fibra em detergente ácido.

${ }^{4}$ Digestibilidade in vitro da matéria seca.

${ }^{1}$ Crude protein.

2 Neutral fiber detergent.

${ }^{3}$ Acid detergent fiber.

${ }^{4}$ In vitro dry matter disappearance.

ganho de peso, que deveriam ser realizadas para que os animais de $1^{\mathrm{a}}$ e $2^{\mathrm{a}}$ parição atingissem o peso adulto na idade adequada (em torno de 700 dias).

Para avaliar os efeitos dos tratamentos, foram realizadas as seguintes medições ao longo do período experimental: produção de leite diária, peso e condição corporal, desempenho reprodutivo.

A produção de leite $(\mathrm{kg} / \mathrm{dia})$ foi o resultado de duas ordenhas diárias, obtidas semanalmente. A variação do peso e condição corporal, ao longo do período experimental, foram acompanhadas mediante pesagem e avaliação, através de palpação mensal dos animais.

A $1^{\text {a }}$ pesagem foi realizada logo após o parto. A metodologia para avaliação corporal dos animais se baseia na palpação em duas regiões, uma ao nível dorso lombar (hipófises) e, outra, no esterno, sendo que, o estado corporal do animal é a média das duas notas (de 0 a 5), coletadas ao nível dorso lombar e no esterno, em uma escala de 0,25.

A disponibilidade de matéria seca (MS) da pastagem ( $\mathrm{kg} \mathrm{MS} / \mathrm{ha}$ ), ao longo do experimento, foi determinada a intervalos de 15 dias, através do método da dupla-amostragem (Wilm et al., 1944). Nestas amostras, foram determinadas: relação folha:caule, fibra em detergente neutro (FDN), fibra em detergente ácido (FDA), nitrogênio insolúvel em detergente ácido (NIDA), proteína bruta (PB) e digestibilidade in vitro da matéria seca (DIVMS).

R. Bras. Zootec., v.31, n.1, p.460-466, 2002 (suplemento)
A pastagem foi manejada com o objetivo de manter um resíduo disponível de, aproximadamente, $3.000 \mathrm{~kg}$ de $\mathrm{MS} / \mathrm{ha}$, ao longo de todo o período experimental. Isto foi obtido através de calagem $(\mathrm{V}=60 \%)$ e adubação $\left(137,13 \mathrm{~kg} \mathrm{~N}, 80 \mathrm{kgP}_{2} \mathrm{O}_{5} \mathrm{e}\right.$ $100 \mathrm{~K}_{2} \mathrm{O}$ )/ha e pelo ajuste da carga animal.

Foram realizadas amostragens mensais do feno e dos concentrados, determinando-se FDN, FDA, NIDA, PB e DIVMS.

A partir do $5^{\circ}$ mês de lactação, toda fêmea que se apresentou no cio foi coberta. A avaliação do desempenho reprodutivo foi feita, considerando-se: intervalo de partos, número de crias por parto, peso da cria ao nascimento e período de serviço.

Os animais foram ordenhados pela manhã (6h) e tarde (15h30). Após a ordenha da manhã, os animais foram levados ao pasto e, após a ordenha da tarde, os animais do sistema semi-confinamento foram recolhidos ao galpão, onde permaneceram durante a noite e receberam feno de gramíneas do gênero Cynodon, à vontade ( $\pm 25 \%$ de sobras). $\mathrm{O}$ feno disponível aos animais do sistema de produção semi-confinamento foi moído, transformando-se em alimento com partículas finas e pulverulento. Os animais do sistema de produção em pastagem permaneceram durante todo o tempo no pasto, tendo como única fonte de volumoso a forragem. Água e sal mineral foram fornecidos à vontade. Cada animal recebeu concentrado, na quantidade determinada, após cada ordenha.

Após o final do período de lactação, os animais permaneceram no mesmo sistema de produção em que já estavam anteriormente, recebendo concentrado para atender a $50 \%$ das exigências de mantença e gestação (NRC, 1981).

Foram realizadas vacinações contra febre aftosa duas vezes ao ano, em maio e outubro. A cada 30 dias, os cascos dos animais foram inspecionados.

As aplicações de antihelmínticos foram feitas apenas nos animais que apresentavam 1.000 ou mais ovos por grama de fezes, e com intervalo de aplicações de, no mínimo, 45 dias.

As amostras dos alimentos foram pré-secadas em estufa de ar forçado a $55^{\circ} \mathrm{C}$ por 72 horas, sendo, posteriormente, moídas em moinho de faca com peneira, com crivos de $1 \mathrm{~mm}$ de diâmetro. As análises de MS, PB e NIDA, foram feitas segundo Silva (1990) e as de FDA e FDN, segundo Goering \& Van Soest (1970), utilizando-se digestor de fibras Fiber Analyser (ANKOM Co. -NY-USA). 
Tabela 2 - Valores médios, máximos e mínimos da composição química e da disgestibilidade in vitro da matéria seca (DIVMS) do pasto e feno

Table 2 - Medium, maximum and minimun values of the chemical composition and in vitro dry matter disappearance (IVDMD) of grass and hay

\begin{tabular}{|c|c|c|c|c|c|c|}
\hline \multirow[t]{2}{*}{$\begin{array}{l}\text { Variáveis (\% da MS) } \\
\text { Variables }(\% \text { DM) }\end{array}$} & \multicolumn{3}{|c|}{$\begin{array}{l}\text { Pasto } \\
\text { Grass }\end{array}$} & \multicolumn{3}{|c|}{$\begin{array}{l}\text { Feno } \\
\text { Hay }\end{array}$} \\
\hline & $\begin{array}{l}\text { Média } \\
\text { Medium }\end{array}$ & $\begin{array}{l}\text { Máximo } \\
\text { Maximun }\end{array}$ & $\begin{array}{l}\text { Mínimo } \\
\text { Minimum }\end{array}$ & $\begin{array}{l}\text { Média } \\
\text { Medium }\end{array}$ & $\begin{array}{l}\text { Máximo } \\
\text { Maximun }\end{array}$ & $\begin{array}{l}\text { Mínimo } \\
\text { Minimum }\end{array}$ \\
\hline $\begin{array}{l}\mathrm{PB}^{1} \\
C P^{1}\end{array}$ & 9,60 & 11,43 & 7,13 & 6,75 & 10,02 & 4,13 \\
\hline $\begin{array}{l}\mathrm{FDN}^{2} \\
N D F^{2}\end{array}$ & 77,56 & 80,42 & 74,55 & 81,30 & 85,39 & 74,96 \\
\hline $\begin{array}{l}\mathrm{FDA}^{3} \\
A D F^{3}\end{array}$ & 41,01 & 43,96 & 37,02 & 44,21 & 48,13 & 40,70 \\
\hline $\begin{array}{l}\text { NIDA }^{4} \\
A D I N^{4}\end{array}$ & 2,29 & 2,73 & 1,82 & 1,96 & 2,91 & 1,02 \\
\hline $\begin{array}{l}\text { DIVMS } \\
I V D M D^{5}\end{array}$ & 50,56 & 55,16 & 43,83 & 45,28 & 53,61 & 31,90 \\
\hline
\end{tabular}

1 Proteína bruta.

2 Fibra em detergente neutro.

${ }^{3}$ Fibra em detergente ácido.

4 Nitrogênio insolúvel em detergente ácido.

${ }^{5}$ Digestibilidade in vitro da matéria seca.

1 Crude protein.

2 Neutral detergent fiber.

${ }^{3}$ Acid detergent fiber.

${ }^{4}$ Acid detergent insoluble nitrogen.

5 In vitro dry matter disappearance.

A digestibilidade in vitro da MS foi feita de acordo com técnica descrita por Tilley \& Terry (1963), adaptada para o uso do rúmen artificial, desenvolvida por ANKOM, conforme descrito por Garman et al. (1997).

As análises laboratoriais foram realizadas no Laboratório de Análises de Alimento e Nutrição, Departamento de Zootecnia, da Universidade Estadual de Maringá.

O delineamento experimental utilizado foi inteiramente casualizado com oito repetições por tratamento (estratégia de suplementação com concentrado ESC.2 do sistema de produção em pastagem, em que foram utilizados sete repetições, uma vez que uma das cabras escolhidas não pariu).

Os efeitos dos tratamentos foram avaliados de acordo com o seguinte modelo estatístico:

$$
\begin{gathered}
\mathrm{Y}_{\mathrm{ijklmn}}=\mu+\mathrm{C}_{\mathrm{i}}+\mathrm{S}_{\mathrm{j}}+\mathrm{AS}_{\mathrm{ij}}+\mathrm{O}_{\mathrm{k}}+\mathrm{G}_{1}+\mathrm{E}_{\mathrm{m}}+\mathrm{b}_{1} \\
(\mathrm{~L}-\mathrm{LM})+\mathrm{b}_{2}(\mathrm{P}-\mathrm{PM})+\mathrm{e}_{\mathrm{ijklmn}}
\end{gathered}
$$

em que: $Y_{\text {ijklmn }}=$ observação no animal n da estratégia de suplementação com concentrado $i$, do sistema de produção $\mathrm{j}$, ordem de parto $\mathrm{k}$, grau de sangue 1 , e época de parto $\mathrm{m} ; \mu=$ constante geral; $\mathrm{C}_{\mathrm{i}}=$ efeito da suplementação com concentrado i; $(i=1$ e 2$)$; $\mathrm{S}_{\mathrm{j}}=$ efeito do sistema de produção $\mathrm{j} ;(\mathrm{j}=1$ e 2$)$;
$\mathrm{AS}_{\mathrm{ij}}=$ efeito da interação entre a suplementação com concentrado i e o sistema de produção $\mathrm{j} ; \mathrm{O}_{\mathrm{k}}=$ efeito da ordem de lactação $\mathrm{k} ;(\mathrm{k}=1 \ldots 4) ; \mathrm{G}_{1}=$ efeito do grau de sangue $1 ;(1=1 \ldots 3) ; \mathrm{E}_{\mathrm{m}}=$ efeito da época de parto $\mathrm{m} ;(\mathrm{m}=1$ e 2$) ; \mathrm{b}_{1}=$ coeficiente linear de regressão da variável $\mathrm{Y}$, em função da produção de leite nos primeiros 21 dias pós-parto; $b_{2}=$ coeficiente linear de regressão da variável $Y$, em função do peso ao parto; $\mathrm{L}=$ produção de leite do animal 1 nos 21 dias pósparto; $\mathrm{LM}=$ média da produção de leite nos 21 dias pós-parto; $\mathrm{P}=$ peso ao parto do animal $1 ; \mathrm{PM}=$ média de peso ao parto; $\mathrm{e}_{\mathrm{ijklmn}}=$ erro aleatório associado a cada observação.

\section{Resultados e Discussão}

As Figuras 1, 2 e 3 mostram os resultados da qualidade do pasto, disponibilidade de matéria seca, carga animal e qualidade do feno, ao longo do período experimental. Verifica-se que a disponibilidade de matéria seca total do pasto, ao longo do experimento, quase sempre foi superior a $3.000 \mathrm{~kg} / \mathrm{ha}$, condizendo com o objetivo proposto neste estudo (Figura 3). A disponibilidade de matéria seca total inferior a $3.000 \mathrm{~kg} / \mathrm{ha}$, no início do experimento, 


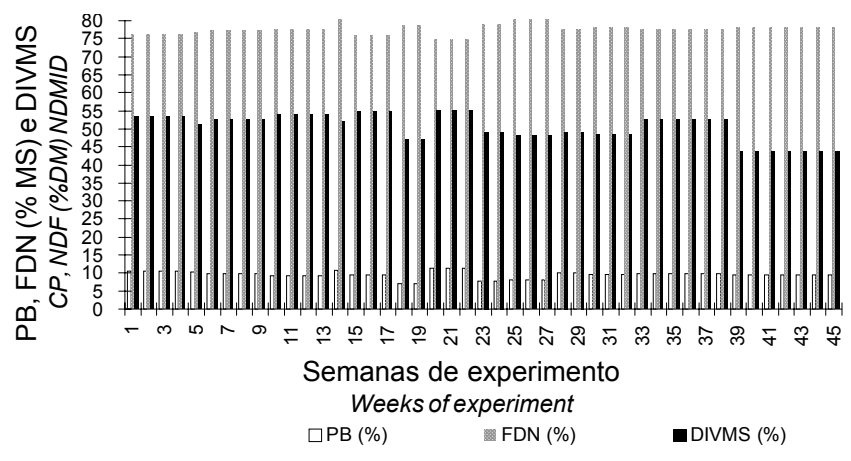

Figura 1 - Variação da qualidade do pasto, ao longo do experimento.

Figure 1 - Qualite variation of grass during experiment.

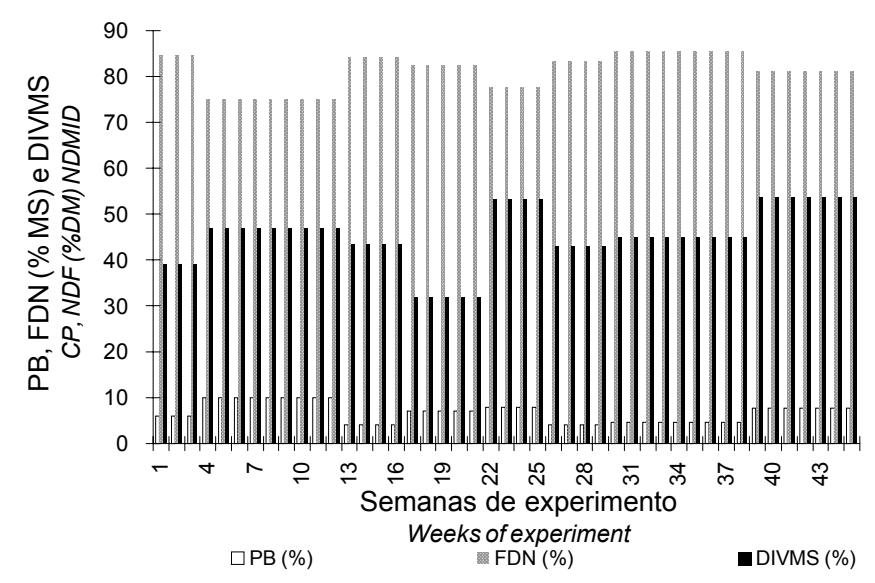

Figura 2 - Variação da qualidade do feno ao longo do experimento.

Figure 2 - Qualit variation of hay during experiment.

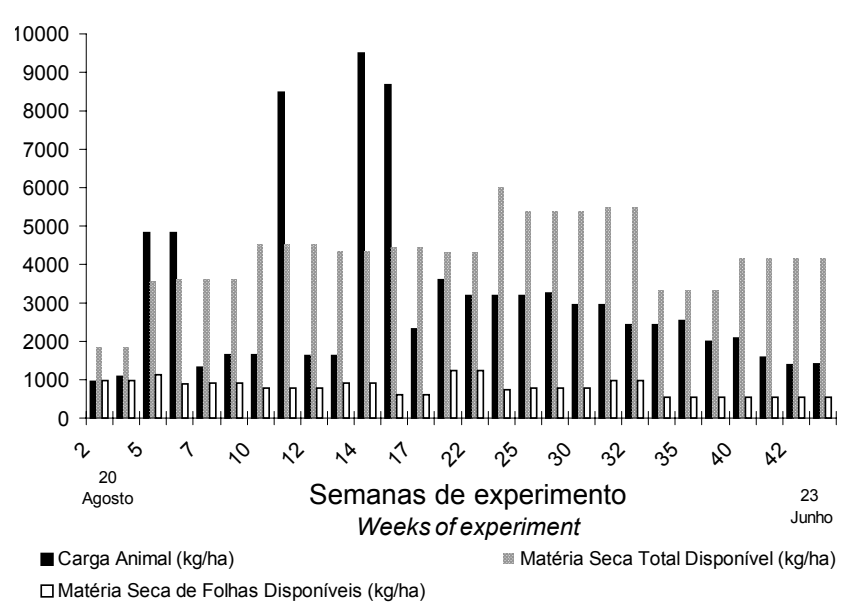

Figura 3 - Disponibilidade de matéria seca da folha, matéria seca total do pasto, ao longo do experimento e carga animal.

Figure 3 - Dry matter disponibility of leaf, total dry matter of grass during experiment and stocking rate.

R. Bras. Zootec., v.31, n.1, p.460-466, 2002 (suplemento) ocorreu, provavelmente, pelo efeito do inverno, uma vez que o experimento iniciou-se praticamente no final do mesmo.

Os valores de PB, FDN e DIVMS do pasto tiveram uma pequena variação, ao longo do experimento, em que, principalmente, os valores de DIVMS foram inferiores aos valores esperados. Já no feno, ocorreu uma maior variação dos componentes ao longo do experimento, sendo que os valores de PB e DIVMS foram aquém do esperado, principalmente, em determinadas semanas de experimento. Este resultado, provavelmente, pode estar relacionado ao fato de que o feno disponível na alimentação dos animais deste experimento foi oriundo de épocas e propriedades diferentes.

$\mathrm{O}$ sistema de produção teve efeito $(\mathrm{P} \leq 0,05)$ nas variáveis consumo total de concentrado e produção total de leite, mostrando que o sistema de produção em pastagem proporcionou maior produção de leite, mas não afetou a produção de leite/ consumo de concentrado. No entanto, o consumo total de concentrado foi maior, uma vez que a correção da quantidade de concentrado, oferecida aos animais, estava relacionada às exigências dos animais (Tabela 3).

A maior produção de leite obtida no sistema de produção em pastagem, provavelmente, é atribuída à melhor qualidade do pasto, comparado à qualidade do feno, como mostram as Figuras 1 e 2, e à maior possibilidade de seleção pelos animais neste sistema, pois o feno foi ofertado triturado.

As variáveis consumo total de concentrado e produção de leite/consumo de concentrado sofreram efeito $(\mathrm{P} \leq 0,05)$ da estratégia de suplementação com concentrado, sendo que a ESC.1 resultou em maior valor de produção de leite/consumo de concentrado e inferior para consumo total de concentrado. A produção total de leite não foi afetada $(\mathrm{P}>0,05)$ pela estratégia de suplementação com concentrado.

A não influência da estratégia de suplementação com concentrado sobre a produção total de leite, obtidos neste trabalho, estão de acordo com resultados encontrados por Aston et al. (1995), trabalhando com estratégia de suplementação, com concentrado em vacas Holandesas, em que não houve diferença na produção total de leite. Resultado semelhante foi relatado por Rubino et al. (1995), avaliando diferentes estratégias de suplementação em cabras da raça Maltese e Rossa Mediterranea, quando não obtiveram diferença na produção total de leite. 
No entanto, Crespo et al. (1995), avaliando efeito de duas estratégias de suplementação em cabras da raça Verata, obtiveram diferença $(\mathrm{P} \leq 0,05)$ sobre a produção total de leite. A maior produção foi obtida para o grupo de animais que recebeu suplementação de $750 \mathrm{~g}$ de concentrado/dia.

Verifica-se pela Tabela 4, que o sistema de produção teve efeito $(\mathrm{P} \leq 0,05)$ sobre o peso corporal, sendo a média do peso corporal do sistema de produção em pastagem superior ao sistema semi-confinamento. Já a condição corporal não sofreu efeito $(\mathrm{P}>0,05)$ do sistema de produção.

Isto demonstra que animais que consumiram feno de baixa qualidade, no período noturno, não conseguiram compensar a ingestão de nutrientes na pastagem, durante o período diurno, destacando-se a importância da ingestão de volumosos no período noturno para o bom desempenho dos animas, nas condições de manejo e ambiente da presente pesquisa.

Houve variação $(\mathrm{P} \leq 0,05)$ da resposta do peso e condição corporal à estratégia de suplementação, com concentrado, em função do sistema de produção.

No sistema de produção semi-confinamento, a ESC.2 resultou em valor superior para a condição corporal $(\mathrm{P} \leq 0,05)$, sendo que o peso corporal não sofreu efeito da estratégia de suplementação com concentrado $(\mathrm{P}>0,05)$.

No sistema de produção em pastagem, o peso e a condição corporal sofreram efeitos $(\mathrm{P} \leq 0,05)$ da estratégia de suplementação, com concentrado, em que a ESC. 1 resultou em maiores valores de peso e condição corporal.

Como não houve aumento na produção de leite nos animas do tratamento ESC.2, em resposta ao maior consumo de concentrado, esperava-se que estes animas exibissem peso e condição corporal superiores aos demais; isto ocorreu apenas no sistema semi-confinado. Talvez, isto indique que no sistema a pasto, em que o volumoso era de qualidade superior e as possibilidades de seleção eram maiores, houve substituição de volumoso pelo concentrado.

Os parâmetros reprodutivos, intervalo de partos, número de crias por parto, peso da cria ao nascimento e período de serviço não foram influenciados pela estratégia de suplementação com concentrado e sistema de produção $(\mathrm{P}>0,05)$, apresentando as médias de 344,64 dias; 1,55 crias; 4,38 $\mathrm{kg}$ e 194,64 dias, e desvio-padrão 46,$34 ; 0,54 ; 1,79$ e 46,34, respectivamente.

R. Bras. Zootec., v.31, n.1, p.460-466, 2002 (suplemento)
Tabela 3 - Médias do consumo total de concentrado (CONTOT), produção total de leite (PROTOT) e produção de leite/consumo de concentrado (LEICON)

Table 3 - Average total intake of concentrate (CONTOT), total milk production (PROTOT) and milk production/ concentrate intake ratio (LEICON)

\begin{tabular}{|c|c|c|c|c|}
\hline \multirow{2}{*}{\multicolumn{2}{|c|}{$\begin{array}{l}\text { Fatores } \\
\text { Factors }\end{array}$}} & \multicolumn{3}{|c|}{$\begin{array}{l}\text { Variáveis } \\
\text { Variables }\end{array}$} \\
\hline & & $\begin{array}{c}\text { CONTOT }(\mathrm{kg}) \\
\text { CONTOT }\end{array}$ & $\begin{array}{c}\text { PROTOT }(\mathrm{kg}) \\
\text { PROTOT }\end{array}$ & $\begin{array}{l}\text { LEICON } \\
\text { LEICON }\end{array}$ \\
\hline${ }^{1}$ Sis. 1 & & $46,85^{b}$ & $216,33^{b}$ & 4,59 \\
\hline${ }^{2}$ Sis. 2 & & $84,69^{\mathrm{a}}$ & $370,03^{\mathrm{a}}$ & 4,21 \\
\hline${ }^{3} \mathrm{ESC} .1$ & & $55,82^{b}$ & 280,96 & $4,91^{\mathrm{a}}$ \\
\hline${ }^{4}$ ESC. 2 & & $75,13^{\mathrm{a}}$ & 301,09 & $3,86^{\mathrm{b}}$ \\
\hline \multirow[t]{2}{*}{${ }^{1}$ Sis. 1} & ${ }^{3}$ ESC. 1 & $34,15^{\mathrm{b}}$ & 180,75 & $5,20^{\mathrm{a}}$ \\
\hline & ${ }^{4} \mathrm{ESC} .2$ & $59,55^{\mathrm{a}}$ & 251,08 & $3,98^{\mathrm{b}}$ \\
\hline \multirow[t]{2}{*}{${ }^{2}$ Sis. 2} & ${ }^{3}$ ESC.1 & $77,49^{\mathrm{b}}$ & 381,16 & $4,62^{\mathrm{a}}$ \\
\hline & ${ }^{4}$ ESC. 2 & $92,93^{\mathrm{a}}$ & 357,31 & $3,73^{\mathrm{b}}$ \\
\hline \multicolumn{2}{|c|}{${ }^{5} \mathrm{CV}(\%)$} & 16,77 & 29,85 & 15,03 \\
\hline
\end{tabular}

1 Sistema de produção semi-confinado.

2 Sistema de produção a pasto.

$330 \%$ das exigências em energia líquida (NRC, 1981) da $3^{a}$ semana até o final da lactação.

$460 \%$ das exigências em energia líquida diária da $3^{a}$ a $13^{a}$ semana, e $15 \%$ das exigências (NRC, 1981) em EL da $14^{a}$ semana até o final da lactação.

5 Coeficiente de variação.

$a, b=$ Médias com letras distintas na mesma coluna diferem entre si $(\mathrm{P} \leq 0,05)$.

1 Semi feedlot production system.

2 Grass production system.

$330 \%$ of net energy requirement (NRC, 1981) from third week until the end of lactation.

$460 \%$ of net energy requirement from $3^{\text {th }}$ to $13^{\text {th }}$ lactation weeks, and $15 \%$ of NE requirements from $14^{\text {th }}$ to end of lactation (NRC, 1981).

5 Coefficient of variation.

${ }^{6} a, b=$ Average with different letters at the same row are different $(P \leq .05)$.

Este resultado, em relação ao intervalo de partos e período de serviço, provavelmente, pode estar relacionado ao "efeito macho," manejo que consiste em introduzir o reprodutor junto ao rebanho, com a finalidade de induzir as fêmeas a entrarem em cio. A introdução dos machos só ocorreu a partir do mês de abril, momento em que a maioria das cabras já estavam no final da lactação, ou já estavam secas. Outro motivo seria a estacionalidade reprodutiva natural de caprinos de origem européia que apresentam atividade reprodutiva concentrada nos meses de outono.

Para os animais que já tinham finalizado a lactação, o manejo alimentar adotado fez com que todos os animais recebessem concentrado suficiente para atender suas exigências, propiciando aos mesmos condições adequadas de reprodução. 
Tabela 4 - Médias do peso e condição corporal dos animais Table 4 - Average of body weight and body condition of animals

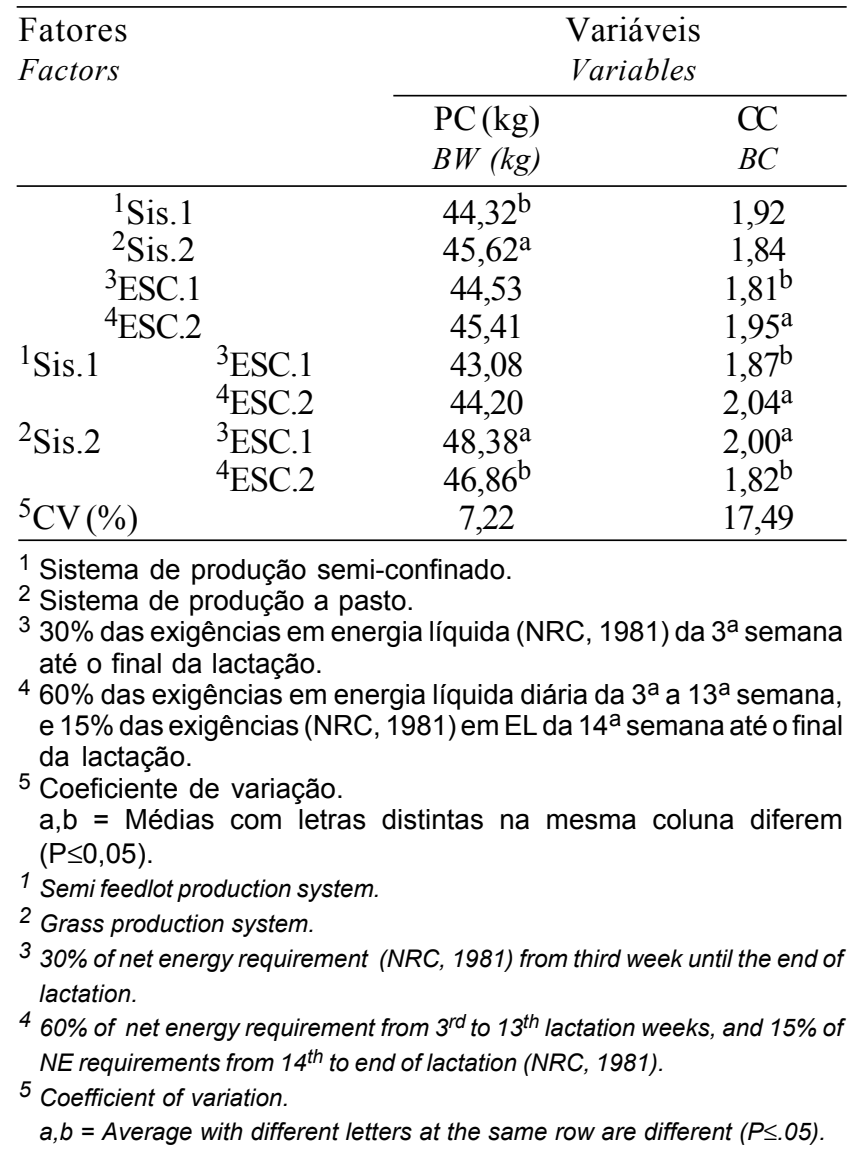

\section{Conclusões}

O sistema de produção em pastagem apresentou o melhor resultado de produção total de leite, embora este resultado seja devido, em parte, à qualidade e forma física do feno utilizado.

A melhor relação produção de leite/consumo de concentrado foi encontrada na estratégia de suplementação com concentrado, ESC.1 (30\% das exigências em energia líquida (NRC, 1981) da $3^{\mathrm{a}}$ semana até o final da lactação).

No sistema de produção em pastagem, a ESC. 1 apresentou valores superiores para peso e condição corporal.

As variáveis reprodutivas não sofreram efeitos da estratégia de suplementação com concentrado e do sistema de produção.

\section{Literatura Citada}

ASTON, K.J.; SUTTON, D.; FISHERT, W.J. Milk production from grass silage diets: strategies for concentrate allocation. Animal Science, v.65, p.465-480. 1995.

CRESPO, J.G.; LOZANO, M.; SERRANO, A. Yield and chemical composition of milk of the Verata goat. Alimentaria, v.33, n.263, p.53-58, 1995.

DAMASCENO, J.C.; FERREIRA, A.C.D.; GEAHL, S.E. et al. Responses of the dairy goats supplemented with different levels of concentrate. Journal Dairy Science, v.80, S.1, p.462, 1997.

GARMAN, C.L.; HOLDEN, L.A.; KANE, H.A. Comparison of in vitro dry matter digestibility of nine feedstuffs using three methods of analysis. Journal Dairy Science, v.80, S1, p.260, 1997

GOERING, H.K.; VAN SOEST, P.J. Forage fiber analyses. Washington: USDA, 1970. (Handbook, 379)

LUCCI, C.S. Manejo de vacas leiteiras a pasto. Revista Leite B. Caderno de tecnologia, v.86, p.145-147. 1993.

NUTRIENT REQUIREMENTS OF GOATS - NRC. Washington, D.C.: National Academy Press, 1981. 91p.

RUBINO, R.; MOIOLI, B.; FEDELE, V. et al. Milk production of goats grazing native pasture under different supplementation regimes in southern Italy. Small Ruminants Research, v.17, n.3, p.213-221, 1995.

SANTOS, L.E. Hábitos e manejo de caprinos In: ENCONTRO NACIONAL PARA O DESENVOLVIMENTO DA ESPÉCIE CAPRINA, 3., 1994, Jaboticabal. Anais... Jaboticabal: Universidade Estadual de São Paulo, 1994. p.1.

SILVA, D.J. Análise de alimentos (métodos químicos e biológicos). 2.ed. Viçosa, MG: Universidade Federal de Viçosa, 1990. 65p.

SINGH, N.P. Supplementary feeding of goats during lactation. Indian Journal of Small Ruminants, v.2, n.1, p.7-10, 1996.

TILLEY, M.A.; TERRY, R.A. A two-stage technique for the in vitro digeston of forage, crops. Journal of the British Grassland Society, v.18, p.104-111, 1963.

VILELA, D.; ALVIM, M.J.; REZENDE, J.C. Efeito do concentrado de alta densidade energética no início da lactação sobre a produção de leite em pastagens de coastcross (Cynodon dactilon L). In: REUNIÃO ANUAL DA SOCIEDADE BRASILEIRA DE ZOOTECNIA, 34., 1997, Juiz de Fora. Anais... Juiz de Fora: 1997. p.240-242.

WILM, H.G.; COSTELLO, O.F.; KLIPPLE, G.E. Estimating forage yield by the double sampling method. Journal of American Society Agriculture, v.36, n. 1, p.194-203, 1944.
Recebido em: 30/06/99 Aceito em: 03/10/01 